\title{
Mitochondrial Genome (mtDNA) and Human Diseases
}

\author{
Ronnie L. Davidson \\ Genetic Screening and Diagnostics for Rare Diseases (GSDRD), Biopharma, Inc., Raleigh, NC 27612, USA \\ Correspondence to: Dr. Ronnie L. Davidson, Pharm.D., E-mail: rldavidson@biopharma.com \\ DOI: https://doi.org/10.15354/si.21.re201 \\ The author declares no competing interest.
}

\begin{abstract}
Mitochondria not only provide necessary energy for cells, but more importantly, they participate in the regulation of various biological functions and activities of cells. As one of the critical components of the body's genome, mitochondrial genome (mtDNA) is the key to cell bioenergetics and genetics. However, since no protection of histones and a complete self-repair system, mtDNA is extremely prone to mutate. Human diseases caused by mtDNA mutations are only transmitted through the maternal line. The same phenotype can come from multiple mtDNA mutations, and the same mtDNA mutation can lead to multiple phenotypes. This is the major reason that makes the diagnosis and identification of mtDNA genetic diseases difficult. Meanwhile, mtDNA mutations may be the culprit involved in mediating the aging and tumorigenesis. Currently, no effective therapeutics for diseases caused by mtDNA mutations, but with the deepening of research and technological advancement, it is promising that breakthroughs in the diagnosis and treatment of mitochondrial-related diseases in the near future.
\end{abstract}

Keywords: Mitochondrial DNA; Diseases; Genetics; Mutation; Therapeutics

Science Insights, 2021 September 17; Vol. 38, No. 4, pp.317-325.

(C) 2021 Insights Publisher. All rights reserved.

Creative Commons Non Commercial CC BY-NC: This article is distributed under the terms of the Creative Commons Attribution-NonCommercial 4.0 License which permits non-commercial use, reproduction and distribution of the work without further permission provided the original work is attributed by the Insights Publisher.

\footnotetext{
A SINGLE cell in human body contains about 200-2,000 mitochondria with the largest number found in the most metabolically active cells like brain, heart, and skeletal muscles. The main function of mitochondria is to provide energy for cell activities through the respiratory chain, that is, the electron transport chain and the oxidative phosphorylation system, and also participate in some important metabolic pathways (1). In addition, mitochondria are also related to the production of reactive oxygen species (ROS), cell apoptosis, and autophagy $(2,3)$. There are more than 1,000 kinds of proteins that make up mitochondria. Except for the respiratory chain complex protein which is double-encoded by mitochondrion genome (mtDNA) and nuclear genes, all other proteins are encoded by nuclear genes. Therefore, mtDNA mutations or nuclear gene mutations may cause mitochondrial dysfunction $(4,5)$.
}

Mitochondrial disease is a general term for a large group of diseases caused by mitochondrial dysfunction. This concept was proposed by Luft et al. in 1962 in the skeletal muscle cells of a young woman with hypermetabolism but normal thyroid function, which discovered a large number of mitochondria with loose coupling of oxidative phosphorylation (6). In 1988, Holt et al. found large mtDNA deletion mutations in some patients with spontaneous neuromuscular diseases (7). Subsequently, Wallace et al. found a point mutation in mtDNA from a patient with Leber Hereditary Optic Neuropathy (LHON) $(8,9)$. So far, more than $250 \mathrm{mtDNA}$ point mutations and a large number of mtDNA recombination mutations have been reported and are related to human diseases (11).

In this review, we summarize the genetic characteristics of mitochondria, mtDNA mutations and human genetic diseases, 


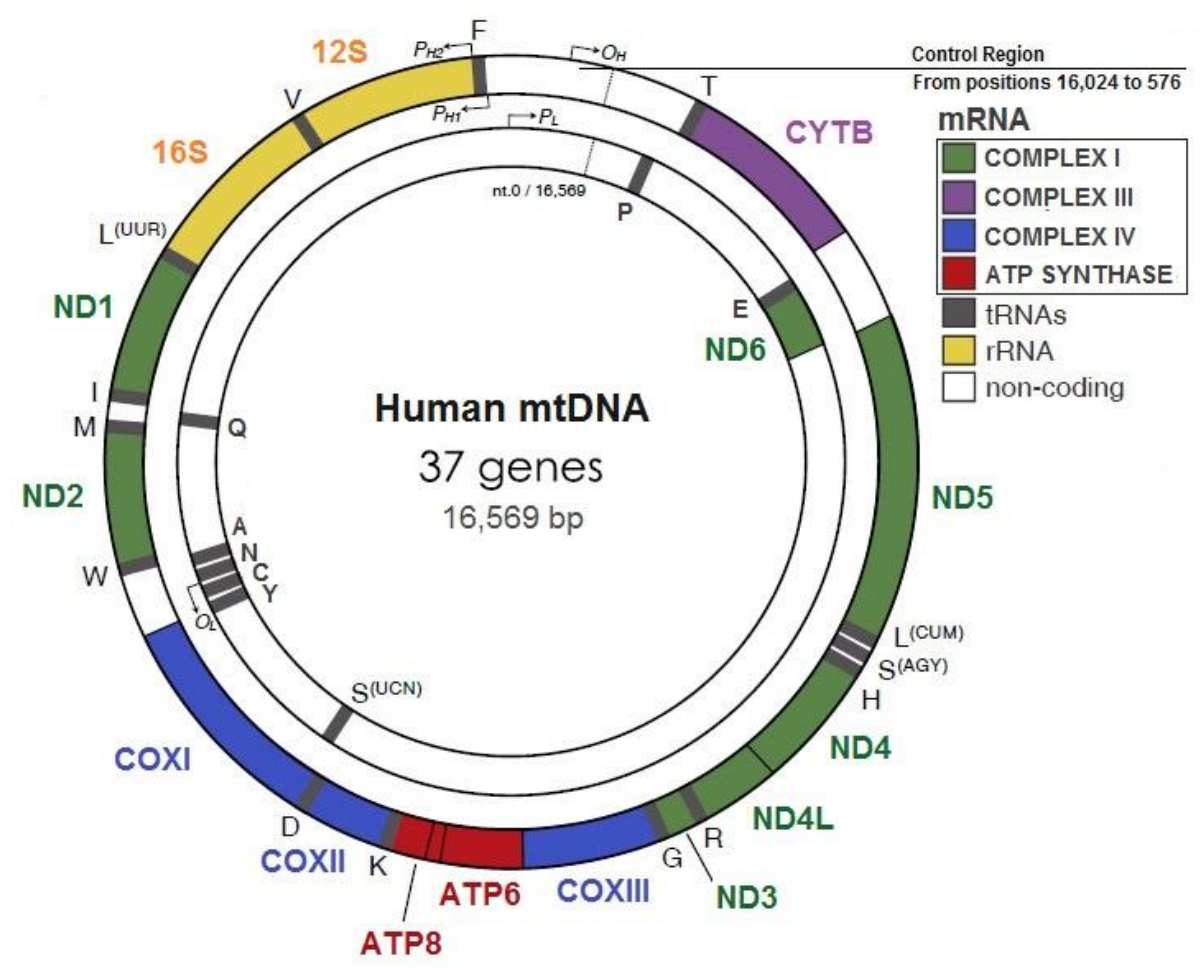

Figure 1. mtDNA Structure.

(Modified from Mitochondrion 2016;30:105-116.)

the role of somatic mtDNA mutations in aging and tumors, and the diagnosis and management of mtDNA diseases.

\section{Mitochondrial Genetics}

Mitochondria are the only organelles in human cells that have their own genetic material except for the nucleus. Compared with nuclear genes, the mitochondrial genome has its specific features (5). mtDNAs exist in mitochondria and cells in multiple copies. They encode 7 NADH-ubiquinone reductase ND subunits (ND1, ND2, ND3, ND4, ND4L, ND5 and ND6), 1 cytochrome b subunit (Cytb), and 3 cytochrome $\mathrm{C}$ oxidase subunits (COX I, COX II and COX III), 2 ATP synthase subunits (ATP6 and ATP8), 2 rRNAs (12S and 16S ribosomal RNA) and 22 tRNAs (Figure 1) (12). The characteristics of mitochondrial remains can be summarized in 4 aspects: (i) maternal inheritance (ii) heterogeneity and mutation load; (iii) threshold effect; (iv) "bottleneck" and random allocation.

\section{Maternal versus Paternal Inheritance}

Giles et al. performed single nucleotide polymorphism analysis on mitochondrial genes of several European families and found that mtDNA molecules were transmitted strictly in accordance with the maternal inheritance method. Maternal inheritance means that only mothers can pass their mtDNA molecules to the next generation, and then to the offspring through their daughters (13). Schwartz et al. found a 2-bp deletion mutation in the MTND2 gene of mtDNA in the muscle tissue of a patient with mitochondrial myopathy (MM) (14). Even though the gene haplotype analysis showed that this mutated mtDNA molecule originated from the patient's father, although the mutation may spontaneously form in early embryogenesis (14), subsequent related studies have not found traces of mitochondrial paternal inheritance $(15,16)$. As mentioned by Sutovsky et al. that sperm mitochondria will be specifically recognized and degraded by ubiquitin hydrolase in the egg during the process of fertilization $(17,18)$. This explains the phenomenon that only maternal but not paternal $\mathrm{mtDN}$ be transmitted to the offspring. Interestingly, if the egg fails to prevent the mtDNA in the sperm from entering it during fertilization, the resulting fertilized egg will be lost due to abnormal development (19). Therefore, in the diagnosis and genetic consultation of mtDNA mutations and related diseases, maternal inheritance should be regarded as the basic rule of mitochondrial inheritance (see the sample pedigree diagram of mtDNA disease in Figure 2).

\section{Heterogeneity and Mutation Load}

Nuclear gene mutations occur on alleles, and the resulting mutants are divided into homozygote (homozygote, mutation load is $100 \%$ ) versus heterozygote (heterozygote, mutation load is $50 \%$ ). Unlike nuclear genes, mitochondrial gene mutations can occur in thousands of mtDNA molecules, resulting in mtDNA mutants with mutations ranging from $0 \%$ to $100 \%$. Mutation load refers to the percentage of mtDNA that undergoes mutations in the total mtDNA, and it is an important indicator to measure the degree of heterogeneity of mtDNA mutants. The occurrence of mtDNA disease and its clinical phenotype often 


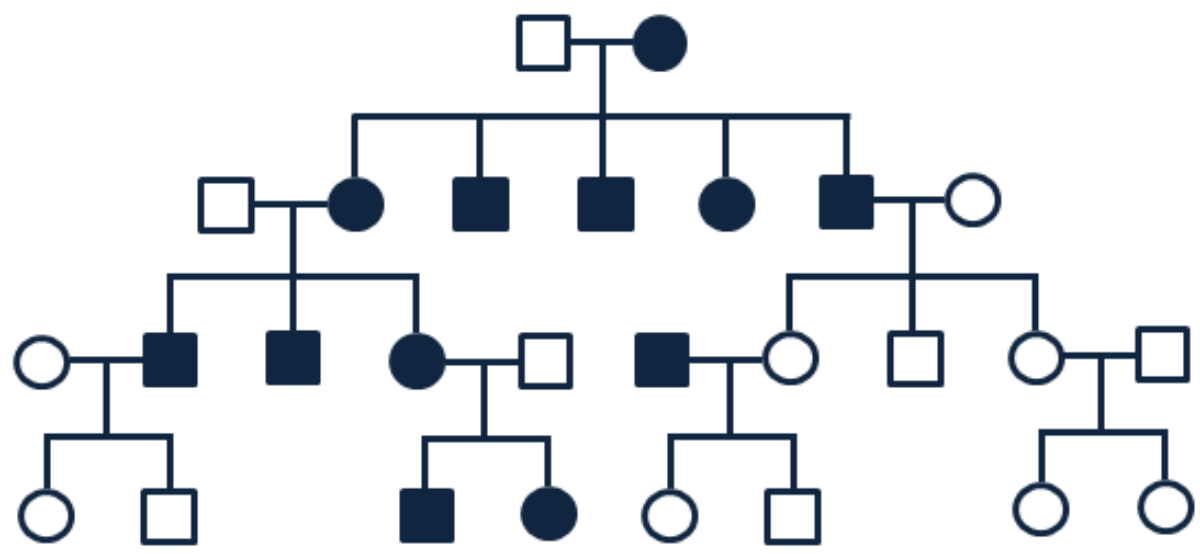

Figure 2. Pedigrees and Patterns of Mitochondrial Inheritance.

depend on the mutation load. Jeppesen and colleagues revealed that when the mutation load of the mt-A3243G point mutation in human muscle reaches $50 \%$, it is sufficient to cause oxidative damage to skeletal muscle cells and abnormal muscle tissue morphology (20). In addition, the A3243G mutation load is positively correlated with the severity of the disease (21).

\section{Threshold Effect}

When the mutation load of the heterogeneous mtDNA mutant is low, the wild-type mtDNA coexisting with the mutant mtDNA will exert sufficient compensation to maintain the function of the mitochondrial respiratory chain. However, when the mutation load exceeds a certain range, making the amount of wild-type mtDNA insufficient to maintain the function of the respiratory chain that results in the tissues or organs be abnormal This phenomenon is called the threshold effect (23). Different human tissues and organs have different susceptibility to mtDNA mutations. Those parts with high energy requirements such as skeletal muscle, brain, heart, renal tubules and endocrine glands, are susceptible to mutations, and thereby a lower mutation load will cause clinical symptoms in these tissues. But those parts with low energy requirements such as the lungs, skin, and ligaments are not sensitive to mutations, and so a higher mutation load is needed for causing abnormalities.

\section{"Bottleneck" and Random Allocation}

The mutation load of heterogeneous mtDNA changes significantly between different generations. This effect is the "bottleneck" of mitochondrial inheritance. A widely accepted hypothesis is that in the early stage of oogenesis, the amount of mtDNA in the primordial oocyte will decrease sharply, resulting in a "bottleneck" (23). However, the count of mtDNA in a single mouse germ cell showed that the primordial oocyte contains a stable and moderate number of mtDNA copies in the primary and intermediate stages of oogenesis $(24,25)$. At the maturation stage of primary oocytes, the number of mtDNA will increase substantially. This shows that the "bottleneck" is not caused by the sharp decrease in the number of mtDNA in the early stage of oogenesis, but because the oocyte has undergone multiple divisions so that the effective amount of mtDNA that is finally allocated to each egg is small.

During mitosis (including oogenesis), mtDNA is randomly allocated to progeny cells. In oocytes, about 150,000 mtDNA molecules exist. After oogenesis, only part of mtDNA enters the primary oocytes, forming a population of oocytes with very different levels of heterogeneity; the experience of fertilized eggs after fertilization During cleavage and embryo development, only a few copies of mtDNA molecules finally enter the neonatal tissue cells $(24,26)$. Therefore, the disease phenotype between members of the same maternal family and the mutation burden between the same patient's tissues are often very different. Every time a somatic cell undergoes mitosis, mtDNA will be randomly assigned to the progeny cells along with the mitochondria. Therefore, the mutation load of mtDNA in the tissue will change with the division of tissue cells. Furthermore, the disease phenotype of the same patient can also show variability over time.

\section{mtDNA Mutations and Diseases Mutations in mtDNA and Human Genetic Dis- eases}

The mutation rate of mtDNA is extremely high due to the lack of histone protection and intact mutation repair function, (27). The high mutation rate of the mitochondrial genome not only produces a large number of pathogenic mutants, but also produces more sequence polymorphisms. Pathogenic mtDNA mutations generally have the following characteristics: (i) The mutation site is relatively conservative, and the mutation results in nucleotide or amino acid substitution, or loss of biological function of the gene-coded product. (ii) The biochemical damage caused by the mutation can be separated from the clinical phenotype of the disease. (iii) When the mutation is a heterogeneous mutation, the degree of tissue damage is positively correlated with the mutation load. (iv) The same mutation can be found in 
genetically independent patients.

Pathogenic mtDNA mutations are usually located in genes encoding proteins, tRNAs or rRNAs, and can cause obvious clinical symptoms (28). The relationship between mtDNA mutation and phenotype is complex. The same mtDNA mutation can cause different disease phenotypes. For example, the A3243G mutation in the tRNALeu (UUR) gene can appear in patients with mitochondrial encephalopathy, lactic acidosis, and stroke-like episodes (MELAS), as well as chronic progressive external ophthalmoplegia (CPEO), mitochondrial myopathy, and diabetic patients with deafness. In addition, the same disease phenotype can also be caused by different mutations. For example, MELAS can be caused by more than 20 point mutations, or it can be caused by recombinant mutations. Some independent factors can affect the clinical manifestations of mtDNA diseases, including: the level of heterogeneity of mutants, tissue distribution, and the degree of dependence of organs on the respiratory chain, nuclear background, and environmental factors.

mtDNA mutations can be divided into two categories: point mutations and recombination mutations.

\section{Point Mutation}

Human genetic diseases related to mtDNA point mutations mainly include: LHON, MELAS, myoclonus epilepsy associated with ragged-red fibers (MERRF), neuropathy ataxia and retinitis pigmentosa (NARP), maternally inherited Leigh-like syndrome (MILS), maternally inherited diabetes and deafness (MIDD), nonsyndromic hearing impairment (NSHI), cardiomyopathy and myoglobinuria (27). In addition, mtDNA point mutations are also related to the susceptibility of some metabolic diseases (such as hypertension, diabetes, hypercholesterolemia, etc.) and neurodegenerative diseases (such as Parkinson's disease, Alzheimer's disease, etc.) (29).

\section{- LHON}

LHON was the first maternal genetic disease identified with mtDNA point mutations (8). Clinically, it is characterized by continuous acute or subacute central vision loss on both sides, which mainly affects adolescent males. Most of the point mutations associated with LHON are located in the MTND gene. Three primary mtDNA mutations G11778A, G3460A and T14484C are located on the MTND4, MTND1 and MTND6 genes, respectively. The cases caused by these mutations account for about $95 \%$ of all LHON patients. The penetrance of LHON-related mutants varies greatly, and different mutants have different penetrance, even if the penetrance of the same mutant is different among different individuals (30).

\section{- MELAS}

MELAS is a group of mtDNA diseases with high clinical variability and genetic heterogeneity. Its main characteristics are: (i) Focal damage to the parieto-occipital lobes and the resulting stroke-like episodes; (ii) Lactic acidosis and ragged red fiber (RRF); (iii) Other centers Neurological manifestations, such as dementia, repeated headaches and vomiting, seizures, retinitis pigmentosa, and deafness; (iv) Some patients have manifestations of ataxia; (v) A small number of patients have diabetes, intestinal pseudo-obstruction and cardiomyopathy; (vi) Bio- chemically, mitochondrial complex I is often defective, while complex IV is not easily affected, and the broken red fiber appears to be positive for COX [29]. There are more than 20 mtDNA point mutations related to MELAS. Most cases of MELAS are caused by a heterogeneous mutation A3243G in the mt-tRNALeu (UUR) gene. A few are caused by other mtDNA point mutations and large fragment recombination mutations. There are also some MELAS patients whose mtDNA is normal, suggesting that mutations may occur in nuclear genes (31).

\section{- MERRF}

MERRF's main characteristics are: (i) Myoclonus, epilepsy, muscle weakness and weight loss with broken red fibers; (ii) Cerebellar ataxia, deafness and dementia; (iii) Neurons in the dentate nucleus and secondary lobules of the cerebellum Loss and hypergliosis; (iv) Some patients have symptoms of symmetrical fat increase in the trunk; (v) Biochemically, mitochondrial complex I often has defects, while complex IV is not easily affected, with broken red fibers appearing and most of them are COX negative (32). Most of the mtDNA mutations associated with MERRF are located in the tRNALys gene, of which the A8344G point mutation is the most common. Sometimes, MERRF and MELAS disease phenotypes coexist in the same patient, forming MERRF/MELAS overlap syndrome. Mutations such as mt-A3243G, T8356C and G12147A can respectively cause MERRF/MELAS overlap syndrome (33).

\section{- NARP and MILS}

The main characteristics of NARP are: (i) Ataxia, retinitis pigmentosa, and peripheral neuropathy; (ii) MRI examination revealed that the cerebellum and brain of NARP patients have mild diffuse atrophy, and in severe cases, basic ganglion damage may occur; (iii) Muscle biopsy often fails to detect broken red fibers. MILS is a neurodegenerative disease related to mtDNA mutation in Leigh disease (34). NARP and MILS are usually caused by two heterogeneous mutations $8993 \mathrm{~T}>\mathrm{G} / \mathrm{C}$ located at one locus of the MTA6 gene. The severity of the disease is related to the level of mutant heterogeneity. NAPR can be caused when the mutation load is between 70\%-95\%, and MILS can be caused when the mutation load is higher than $90 \%$.

\section{- Mitochondrial Deafness}

The mt-12S rRNA gene is a mutation hotspot related to deafness. Some point mutations on it such as A1555G, T961C and C1494T, have been confirmed to cause NSHI (35). Another hot spot for mutations is the mt-tRNASer (UCN) gene, such as A7445G, 7472insC and $\mathrm{T} 7511 \mathrm{C}$, which are also related to DEAF. In addition, the point mutation A3243G in the mt-tRNALeu (UUR) gene can cause MIDD (36).

\section{Recombinant Mutation}

Although the length of mtDNA fragments undergoing recombination mutations can vary from one base to several thousand bases, recombination mutations are mainly divided into: deletion and duplication of large fragments.

Deletion mutations can exist alone in the patient, or they can occur at the same time as the doubling. The most common type of recombination mutation is the deletion/doubling of a 
single large fragment of mtDNA that is about $5 \mathrm{~kb}$ in length and spans the region between the Cytb gene and the Cox II gene. This large-segment recombination mutation is usually associated with some typical disease phenotypes, such as Pearson's syndrome, Kearns-Sayre syndrome (KSS), Chronic Progressive External Ophthalmoplegia (CPEO) and Pearson's bone marrow-pancreatic syndrome. However, recombination mutations are not limited to the above-mentioned disease phenotypes, and can also involve diabetes, hearing loss and almost all mitochondrial encephalomyopathy (37).

A single large fragment of mtDNA recombination mutation may be formed during oogenesis or early embryonic development (38). Most of the diseases associated with large deletion/doubling mutations are sporadic and have a low risk of recurrence. Chinnery and colleagues reported that the next generation risk of diseased women is only $4.11 \%$ (39).

\section{Mutations of Somatic mtDNA and Senescence and Tumors \\ Mutation and Aging}

Somatic mtDNA mutations will gradually accumulate as individual's age. Abnormal mtDNA is basically undetectable in the skeletal muscle of people under the age of 40 , while a large number of mtDNA recombination mutations can be found in the skeletal muscle of people over 50, which was considered related to the aging of muscle tissue (40). High-frequency mtDNA deletion mutations were found in the substantia nigra neurons of elderly Parkinson's patients and normal elderly people with higher levels in Parkinson' $s$ patients that was speculated to the aging of brain tissue (41). Meanwhile, ROS-related oxidative damage is another crucial contributor to the somatic mtDNA mutations, and the accumulation of mutations will further damage the function of the mitochondrial respiratory chain, and generate more ROS and mutations, thereby accelerating the aging process (42).

Knock-in was used to establish an mtDNA-mutated mouse model to study the effect of mtDNA mutation on the phenotype of mice and found that these mice have obvious manifestations of premature aging, such as: shortened lifespan, weight loss, osteoporosis, hunchback, cardiac hypertrophy, and fertility decline (43). The in-depth study of mtDNA mutant mice by Kujoth and colleagues revealed that the accumulation of mtDNA mutations does not cause cell proliferation defects, nor is it related to oxidative stress markers, but is closely related to apoptosis markers (44). They also observed similar levels of apoptosis markers in normally aging mice. Therefore, it is speculated that apoptosis caused by the accumulation of somatic mtDNA mutations may be the core mechanism that promotes the aging of mammals. Theoretically, the mtDNA mutant mouse model is a good tool for studying the mechanism of aging, whereas its experimental results cannot confirm absolutely that mtDNA mutations will definitely accelerate the natural aging process of feeding animals. After all, it is impossible to have such a high mtDNA mutation rate in normal aging mice, moreover, mouse models that do not contain mtDNA mutants can also exhibit a premature aging phenotype (45). However, it can still provide indirect evidence that somatic mtDNA mutations may play a key role in human aging.

\section{Mutations and Tumors}

It has been suspected that mitochondrial defects may play an important role in the development of tumors and cancers (46). Although somatic mtDNA mutations can be observed in a variety of tumor cells $(47,48)$, the exact mechanism of these mutations on tumor development is rarely known. Mutations in the MTCOX I gene occurred in $11 \%-12 \%$ of prostate cancer patients in comparison to $7.8 \%$ of healthy controls; the mutation sites on the MTCOX I gene in cancer patients were more conservative in evolution; on the MTATP6 gene, the T8993G point mutation accelerated the formation of tumors of PC3 prostate cancer cells in nude mice, and promoted the production of ROS in tumor tissues (49). When the mitochondrial hybridoma cells containing mutant or wild-type mtDNA were implanted into nude mice, the morphology of tumors formed in mice, and found that mutant mtDNA could obviously promote tumor growth (50). However, when a section of normal mitochondrial gene complementary to the mutant gene is introduced into the nucleus of transmitochondrial hybridoma cells containing mutant mtDNA, the newly constructed tumor cells are then used to infect nude mice. Then the effect of mutant mtDNA to promote tumor growth was substantially inhibited suggesting that mtDNA mutations may promote tumor or cancer development (51).

\section{Diagnosis and Treatment of mtDNA Diseases Diagnosis}

The diagnosis of patients with clinical syndromes is relatively easy. But for patients with atypical symptoms, the diagnosis of mtDNA disease is difficult (52). The precise diagnosis of mtDNA diseases also requires investigations in several aspects: (i) Using histochemical and biochemical methods to determine the exact nature of respiratory chain damage; (ii) Using genetic analysis techniques to find common mtDNA mutations; (iii) The entire mtDNA is sequenced to find rare or new mutations (53). Given the mutation load of heterogeneous mutants in different tissues might be quite different, only by collecting samples from the site of the disease or other sites with higher mutation load can get an ideal diagnosis result (54).

Common mutations can be detected from the patient's tissues through genetic analysis with the combination of the patient's clinical features, the disease can be diagnosed. If a new or rare mtDNA mutation is detected, functional analysis is needed to distinguish the nature of the mutant (55). As indicated that clinical bioinformatics would be a critical tool for analyzing variant and sequencing data available at MSeqDR, MitoMap, and $\mathrm{HmtDB}$ in interpreting mitochondrial DNA variant and helping diagnose the disease (56).

The functional analysis of mutants generally includes: (i) Conservative analysis of the gene site where the mutation is located; (ii) The potential impact of the mutation on the changes in polypeptide hydrophobicity, changes in protein spatial conception, and changes in rRNA and tRNA spatial structure, etc.; (iii) The pathogenic function of mutants. The most commonly used tools for functional studies of mtDNA mutants are transmitochondrial cytoplasmic hybrid and animal model (57). In view of the high variability of mtDNA mutation-related diseases, accurate genetic diagnosis can provide useful clues for 
patient treatment and genetic counseling.

\section{Treatment}

Clinically, medications or supportive therapies are generally used to relieve the symptoms of patients, such as vitamin supplementation, nutrition improvement, treatment of epileptic seizures, adjustment of blood lactic acid levels, surgical correction of blepharoptosis, etc. (58). These methods alleviate the suffering of patients to a certain extent and play a palliative role.

Endurance training can increase the enzyme activity of mitochondria, and it is possible to activate resting cells located between the basal thin layer of muscle fibers and the protoplasmic layer, and promote their differentiation into muscle cells, thereby regulating the mutational load of mtDNA in muscles (59). Endurance training is safe and effective for the treatment of mitochondrial myopathy $(60,61)$. For example, aerobic exercise can improve the respiratory chain function of patients with mitochondrial myopathy, and can reduce the mutation load of mtDNA mutants (62). Continuous endurance training can significantly improve the life and work abilities of patients with mitochondrial myopathy. However, when endurance training is stopped for a period of time, the patient's exercise ability will return to the pre-training level (63).

Antioxidants can relieve the oxidative stress of cells, and can alleviate mitochondrial dysfunction caused by mtDNA mutations (64). Antioxidants $\mathrm{N}$-acetylcysteine, dihydrolipoic acid or CoQ10 to act on cytoplasmic hybrid cells carrying the mt-T8993G mutation and fibroblasts of NARP patients and found that: intracellular reactive oxygen species were decreased; the function of cellular respiratory chain returned to normal; and ATP synthesis ability was also improved $(65,66)$.
In addition, gene therapy uses genetic engineering technology to transplant normal mtDNA genes into the patient's cells to replace or correct the patient's mutant genes, so as to achieve the goal of eradicating mtDNA diseases. In recent years, there has been a lot of research on gene therapy of mtDNA diseases. The wild-type mitochondrial genes were adapted from generalized codons through the nucleus, and the translated protein can use the mitochondrial targeting signal peptide located at its own amino terminus to enter the mitochondria (67). By using nuclear genes to express exogenous mt-tRNA, and got these rRNAs enter the mitochondria of patient cells cultured in vitro, and can be correctly aminoacylated to participate in the mitochondrial protein translation system, thereby protecting cells from mt-tRNA genes. Apoptosis caused by mutation (68). An promising method is that selectively recognize and degrade mutant mtDNA molecules but not the wild-type mtDNA by importing specific restriction endonucleases into human mitochondria, which can achieve the purpose of treatment by reducing the mutation load of some heterogeneous mutants (69-71).

\section{Concluding Remarks}

mtDNA mutations have attracted widespread attention due to its strong causal relationship with human genetic diseases, potential to provide reliable forensic identification, and the underlying key role in the aging and tumorigenesis. However, so far, the pathogenic mechanism of mtDNA mutations has not been clarified at the molecular level, and no effective therapeutics available for mtDNA diseases. However, with the deepening of research and technological progress, it is hopefully obtaining breakthroughs in the diagnosis and treatment of diseases from mtDNA mutations.

\section{References}

1. Evans A, Neuman N. The mighty mitochondria. Mol Cell 2016; 61(5):641. DOI: https://doi.org/10.1016/j.molcel.2016.02.002

2. Cadenas S. Mitochondrial uncoupling, ROS generation and cardioprotection. Biochim Biophys Acta Bioenerg 2018; 1859(9):940-950. DOI: https://doi.org/10.1016/i.bbabio.2018.05.019

3. Abate M, Festa A, Falco M, Lombardi A, Luce A, Grimaldi A, Zappavigna S, Sperlongano P, Irace C, Caraglia M, Misso G. Mitochondria as playmakers of apoptosis, autophagy and senescence. Semin Cell Dev Biol 2020; 98:139-153. DOI: https://doi.org/10.1016/..semcdb.2019.05.022

4. Saki M, Prakash A. DNA damage related crosstalk between the nucleus and mitochondria. Free Radic Biol Med 2017; 107:216-227. DOI:

https://doi.org/10.1016/j.freeradbiomed.2016.11.050

5. Basu U, Bostwick AM, Das K, Dittenhafer-Reed KE, Patel SS. Structure, mechanism, and regulation of mitochondrial DNA transcription initiation. J Biol Chem 2020; 295(52):18406-18425. DOI: https://doi.org/10.1074/jbc.REV120.011202

6. Luft R, Ikkos D, Palmieri G, Ernster L, Afzelius B. A case of severe hypermetabolism of nonthyroid origin with a defect in the maintenance of mitochondrial respiratory control: a correlated clinical, biochemical, and morphological study. J Clin Invest 1962; 41(9):1776-1804. DOI: https://doi.org/10.1172/JCl104637

7. Holt IJ, Harding AE, Morgan-Hughes JA. Deletions of muscle mitochondrial DNA in patients with mitochondrial myopathies. Nature 1988; 331(6158):717-719. 
DOI: https://doi.org/10.1038/331717a0

8. Wallace DC, Singh G, Lott MT, Hodge JA, Schurr TG, Lezza AM, Elsas LJ II, Nikoskelainen EK. Mitochondrial DNA mutation associated with Leber's hereditary optic neuropathy. Science 1988;

242(4884):1427-1430. DOI:

https://doi.org/10.1126/science.3201231

9. Singh G, Lott MT, Wallace DC. A mitochondrial DNA mutation as a cause of Leber's hereditary optic neuropathy. N Engl J Med 1989; 320(20):1300-1305. DOI: https://doi.org/10.1056/NEJM198905183202002

10. Yan C, Duanmu X, Zeng L, Liu B, Song Z. Mitochondrial DNA: Distribution, mutations, and elimination.

Cells 2019; 8(4):379. DOI: https://doi.org/10.3390/cells8040379

11. Ott M, Amunts A, Brown A. Organization and regulation of mitochondrial protein synthesis. Annu Rev Biochem 2016; 85:77-101. DOI: https://doi.org/10.1146/annurev-biochem-060815-014 $\underline{334}$

12. Farge G, Falkenberg M. Organization of DNA in mammalian mitochondria. Int J Mol Sci 2019; 20(11):2770. DOI: https://doi.org/10.3390/ijms20112770

13. Giles RE, Blanc H, Cann HM, Wallace DC. Maternal inheritance of human mitochondrial DNA. Proc Natl Acad Sci USA 1980; 77(11):6715-6719. DOI: https://doi.org/10.1073/pnas.77.11.6715

14. Schwartz M, Vissing J. Paternal inheritance of mitochondrial DNA. N Engl J Med 2002; 347(8):576-580. DOI: https://doi.org/10.1056/NEJMoa020350

15. Taylor RW, McDonnell MT, Blakely EL, Chinnery PF, Taylor GA, Howell N, Zeviani M, Briem E, Carrara F, Turnbull DM. Genotypes from patients indicate no paternal mitochondrial DNA contribution. Ann Neurol 2003; 54(4):521-524. DOI: https://doi.org/10.1002/ana.10673

16. Schwartz M, Vissing J. No evidence for paternal inheritance of mtDNA in patients with sporadic mtDNA mutations. J Neurol Sci 2004; 218(1-2):99-101. DOI: https://doi.org/10.1016/j.jns.2003.11.008

17. Sutovsky P, Moreno RD, Ramalho-Santos J, Dominko T, Simerly C, Schatten G. Ubiquitin tag for sperm mitochondria. Nature 1999; 402(6760):371-372. DOI: https://doi.org/10.1038/46466

18. Sutovsky P, Moreno RD, Ramalho-Santos J, Dominko T, Simerly C, Schatten G. Ubiquitinated sperm mitochondria, selective proteolysis, and the regulation of mitochondrial inheritance in mammalian embryos. Biol Reprod 2000; 63(2):582-590. DOI: https://doi.org/10.1095/biolreprod63.2.582

19. St John J, Sakkas D, Dimitriadi K, Barnes A, Maclin V, Ramey J, Barratt C, De Jonge C. Failure of elimination of paternal mitochondrial DNA in abnormal embryos. Lancet 2000; 355(9199):200. DOI: https://doi.org/10.1016/s0140-6736(99)03842-8

20. Jeppesen TD, Schwartz M, Frederiksen AL, Wibrand F, Olsen DB, Vissing J. Muscle phenotype and mutation load in 51 persons with the 3243A $>$ G mitochondrial DNA mutation. Arch Neurol 2006;
63(12):1701-1706. DOI:

https://doi.org/10.1001/archneur.63.12.1701

21. Frederiksen AL, Andersen PH, Kyvik KO, Jeppesen TD, Vissing J, Schwartz M. Tissue specific distribution of the 3243A->G mtDNA mutation. J Med Genet 2006; 43(8):671-677. DOI: https://doi.org/10.1136/jmg.2005.039339

22. Rossignol R, Faustin B, Rocher C, Malgat M, Mazat JP, Letellier T. Mitochondrial threshold effects. Biochem J 2003; 370(Pt 3):751-762. DOI: https://doi.org/10.1042/BJ20021594

23. Rebolledo-Jaramillo B, Su MS, Stoler N, McElhoe JA, Dickins B, Blankenberg D, Korneliussen TS, Chiaromonte F, Nielsen R, Holland MM, Paul IM, Nekrutenko A, Makova KD. Maternal age effect and severe germ-line bottleneck in the inheritance of human mitochondrial DNA. Proc Natl Acad Sci USA 2014; 111(43):15474-15479. DOI: https://doi.org/10.1073/pnas.1409328111

24. Shoubridge EA, Wai T. Mitochondrial DNA and the mammalian oocyte. Curr Top Dev Biol 2007; 77:87-111. DOI: https://doi.org/10.1016/S0070-2153(06)77004-1

25. Cao L, Shitara H, Horii T, Nagao Y, Imai H, Abe K, Hara T, Hayashi J, Yonekawa H. The mitochondrial bottleneck occurs without reduction of mtDNA content in female mouse germ cells. Nat Genet 2007; 39(3):386-390. DOI: https://doi.org/10.1038/ng1970

26. Chappel $\mathrm{S}$. The role of mitochondria from mature oocyte to viable blastocyst. Obstet Gynecol Int 2013; 2013:183024. DOI: https://doi.org/10.1155/2013/183024

27. Taylor RW, Turnbull DM. Mitochondrial DNA mutations in human disease. Nat Rev Genet 2005; N6(5):389-402. DOI: https://doi.org/10.1038/nrg1606

28. Schon EA, DiMauro S, Hirano M. Human mitochondrial DNA: Roles of inherited and somatic mutations. Nat Rev Genet 2012; 13(12):878-890. DOI: https://doi.org/10.1038/nrg3275

29. McInnes, J. Mitochondrial-associated metabolic disorders: Foundations, pathologies and recent progress. Nutr Metab (Lond) 2013; 10:63. DOI: https://doi.org/10.1186/1743-7075-10-63

30. Kirches E. LHON: Mitochondrial mutations and more. Curr Genomics 2011; 12(1):44-54. DOI: https://doi.org/10.2174/138920211794520150

31. Alston CL, Rocha MC, Lax NZ, Turnbull DM, Taylor RW. The genetics and pathology of mitochondrial disease. J Pathol 2017; 241(2):236-250. DOI: https://doi.org/10.1002/path.4809

32. Phadke R. Myopathology of Adult and Paediatric Mitochondrial Diseases. J Clin Med 2017; 6(7):64. DOI: https://doi.org/10.3390/jcm6070064

33. Campos Y, Martin MA, Lorenzo G, Aparicio M, Cabello A, Arenas J. Sporadic MERRF/MELAS overlap syndrome associated with the 3243 tRNA(Leu(UUR)) mutation of mitochondrial DNA. Muscle Nerve 1996; 19(2):187-190. DOI: https://doi.org/10.1002/(SICI)1097-4598(199602)19:2 $\leq 187::$ AID-MUS10>3.0.CO;2-S

34. Ruhoy IS, Saneto RP. The genetics of Leigh syn- 
drome and its implications for clinical practice and risk management. Appl Clin Genet 2014; 7:221-234. DOI: https://doi.org/10.2147/TACG.S46176

35. Gao Z, Yuan YS. Screening for mitochondrial $12 S$ rRNA C1494T mutation in 655 patients with non-syndromic hearing loss: An observational study. Medicine (Baltimore) 2020; 99(13):e19373. DOI: https://doi.org/10.1097/MD.0000000000019373

36. Jin L, Yang A, Zhu Y, Zhao J, Wang X, Yang L, Sun D, Tao Z, Tsushima A, Wu G, Xu L, Chen C, Yi B, Cai J, Tang X, Wang J, Li D, Yuan Q, Liao Z, Chen J, Li Z, Lu J, Guan MX. Mitochondrial tRNASer(UCN) gene is the hot spot for mutations associated with aminoglycoside-induced and non-syndromic hearing loss.

Biochem Biophys Res Commun 2007;

361(1):133-139. DOI:

https://doi.org/10.1016/j.bbrc.2007.06.171

37. van den Ouweland JM, Lemkes HH, Trembath RC, Ross R, Velho G, Cohen D, Froguel P, Maassen JA. Maternally inherited diabetes and deafness is a distinct subtype of diabetes and associates with a single point mutation in the mitochondrial tRNA(Leu(UUR)) gene. Diabetes 1994; 43(6):746-751. DOI: https://doi.org/10.2337/diab.43.6.746

38. Wallace DC, Chalkia D. Mitochondrial DNA genetics and the heteroplasmy conundrum in evolution and disease. Cold Spring Harb Perspect Biol 2013; 5(11):a021220. DOI: https://doi.org/10.1101/cshperspect.a021220

39. Chinnery PF, DiMauro S, Shanske S, Schon EA, Zeviani M, Mariotti C, Carrara F, Lombes A, Laforet P, Ogier H, Jaksch M, Lochmüller H, Horvath R, Deschauer M, Thorburn DR, Bindoff LA, Poulton J, Taylor RW, Matthews JN, Turnbull DM. Risk of developing a mitochondrial DNA deletion disorder. Lancet 2004; 364(9434):592-596. DOI: https://doi.org/10.1016/S0140-6736(04)16851-7

40. Barazzoni R, Short KR, Nair KS. Effects of aging on mitochondrial DNA copy number and cytochrome $c$ oxidase gene expression in rat skeletal muscle, liver, and heart. J Biol Chem 2000; 275(5):3343-3347. DOI: https://doi.org/10.1074/jbc.275.5.3343

41. Dölle C, Flønes I, Nido GS, Miletic H, Osuagwu N, Kristoffersen S, Lilleng PK, Larsen JP, Tysnes OB, Haugarvoll K, Bindoff LA, Tzoulis C. Defective mitochondrial DNA homeostasis in the substantia nigra in Parkinson disease. Nat Commun 2016; 7:13548. DOI: https://doi.org/10.1038/ncomms13548

42. Hahn A, Zuryn S. Mitochondrial genome (mtDNA) mutations that generate reactive oxygen species. Antioxidants (Basel) 2019; 8(9):392. DOI: https://doi.org/10.3390/antiox8090392

43. Kauppila JHK, Baines HL, Bratic A, Simard ML, Freyer C, Mourier A, Stamp C, Filograna R, Larsson NG, Greaves LC, Stewart JB. A phenotype-driven approach to generate mouse models with pathogenic mtDNA mutations causing mitochondrial disease. Cell Rep 2016; 16(11):2980-2990. DOI: https://doi.org/10.1016/i.celrep.2016.08.037

44. Kujoth GC, Hiona A, Pugh TD, Someya S, Panzer K, Wohlgemuth SE, Hofer T, Seo AY, Sullivan R, Jobling WA, Morrow JD, Van Remmen H, Sedivy JM,
Yamasoba T, Tanokura M, Weindruch $\mathrm{R}$, Leeuwenburgh C, Prolla TA. Mitochondrial DNA mutations, oxidative stress, and apoptosis in mammalian aging. Science 2005; 309(5733):481-84. DOI: https://doi.org/10.1126/science.1112125

45. Geurts J, Nasi S, Distel P, Müller-Gerbl M, Prolla TA, Kujoth GC, Walker UA, Hügle T. Prematurely aging mitochondrial DNA mutator mice display subchondral osteopenia and chondrocyte hypertrophy without further osteoarthritis features. Sci Rep 2020; 10(1):1296. DOI:

https://doi.org/10.1038/s41598-020-58385-w

46. Theurey P, Pizzo P. The aging mitochondria. Genes (Basel) 2018; 9(1):22. DOI: https://doi.org/10.3390/genes9010022

47. Chatterjee A, Mambo E, Sidransky D. Mitochondrial DNA mutations in human cancer. Oncogene 2006;25(34):4663-4674. DOI: https://doi.org/10.1038/sj.onc.1209604

48. Luo Y, Ma J, Lu W. The significance of mitochondrial dysfunction in cancer. Int J Mol Sci 2020; 21(16):5598. DOI: https://doi.org/10.3390/ijms21165598

49. Petros JA, Baumann AK, Ruiz-Pesini E, Amin MB, Sun CQ, Hall J, Lim S, Issa MM, Flanders WD, Hosseini SH, Marshall FF, Wallace DC. mtDNA mutations increase tumorigenicity in prostate cancer. Proc Natl Acad Sci USA 2005; 102(3):719-724. DOI: https://doi.org/10.1073/pnas.0408894102

50. Cruz-Bermúdez A, Vallejo CG, Vicente-Blanco RJ, Gallardo ME, Fernández-Moreno MÁ, Quintanilla M, Garesse R. Enhanced tumorigenicity by mitochondrial DNA mild mutations. Oncotarget 2015; 6(15):13628-13643. DOI:

https://doi.org/10.18632/oncotarget.3698. Erratum in: Oncotarget. 2020; 11(11):1006.

51. Shidara Y, Yamagata K, Kanamori T, Nakano K, Kwong JQ, Manfredi G, Oda H, Ohta S. Positive contribution of pathogenic mutations in the mitochondrial genome to the promotion of cancer by prevention from apoptosis. Cancer Res 2005: 65(5):1655-1663. DOI:

https://doi.org/10.1158/0008-5472.CAN-04-2012

52. Wong LJ. Diagnostic challenges of mitochondrial DNA disorders. Mitochondrion 2007; 7(1-2):45-52. DOI: https://doi.org/10.1016/i.mito.2006.11.025

53. Parikh S, Goldstein A, Koenig MK, Scaglia F, Enns GM, Saneto R, Anselm I, Cohen BH, Falk MJ, Greene C, Gropman AL, Haas R, Hirano M, Morgan P, Sims K, Tarnopolsky M, Van Hove JL, Wolfe L, DiMauro S. Diagnosis and management of mitochondrial disease: A consensus statement from the Mitochondrial Medicine Society. Genet Med 2015; 17(9):689-701. DOI: https://doi.org/10.1038/gim.2014.177

54. Parikh S, Karaa A, Goldstein A, Bertini ES, Chinnery PF, Christodoulou J, Cohen BH, Davis RL, Falk MJ, Fratter C, Horvath R, Koenig MK, Mancuso M, McCormack S, McCormick EM, McFarland R, Nesbitt V, Schiff M, Steele H, Stockler S, Sue C, Tarnopolsky M, Thorburn DR, Vockley J, Rahman S. Diagnosis of 'possible' mitochondrial disease: An existential crisis. J Med Genet 2019; 56(3):123-130. DOI: 
https://doi.org/10.1136/jmedgenet-2018-105800

55. Gorman GS, Chinnery PF, DiMauro S, Hirano M, Koga Y, McFarland R, Suomalainen A, Thorburn DR, Zeviani M, Turnbull DM. Mitochondrial diseases. Nat Rev Dis Primers 2016; 2:16080. DOI: https://doi.org/10.1038/nrdp.2016.80

56. Shen L, McCormick EM, Muraresku CC, Falk MJ, Gai $\mathrm{X}$. Clinical bioinformatics in precise diagnosis of mitochondrial disease. Clin Lab Med 2020; 40(2):149-161. DOI: https://doi.org/10.1016/i.cll.2020.02.002

57. Wilkins HM, Carl SM, Swerdlow RH. Cytoplasmic hybrid (cybrid) cell lines as a practical model for mitochondriopathies. Redox Biol 2014; 2:619-631. DOI: https://doi.org/10.1016/j.redox.2014.03.006

58. Ng YS, Turnbull DM. Mitochondrial disease: genetics and management. J Neurol 2016; 263(1):179-191. DOI: https://doi.org/10.1007/s00415-015-7884-3

59. Taylor AW, Bachman L. The effects of endurance training on muscle fibre types and enzyme activities. Can J Appl Physiol 1999; 24(1):41-53. DOI: https://doi.org/10.1139/h99-005

60. Chilibeck PD, Syrotuik DG, Bell GJ. The effect of concurrent endurance and strength training on quantitative estimates of subsarcolemmal and intermyofibrillar mitochondria. Int J Sports Med 2002; 23(1):33-9. DOI: https://doi.org/10.1055/s-2002-19269

61. Tarnopolsky MA, Rennie CD, Robertshaw HA, Fedak-Tarnopolsky SN, Devries MC, Hamadeh MJ. Influence of endurance exercise training and sex on intramyocellular lipid and mitochondrial ultrastructure, substrate use, and mitochondrial enzyme activity. Am J Physiol Regul Integr Comp Physiol 2007; 292(3):R1271-R1278. DOI:

https://doi.org/10.1152/ajpregu.00472.2006

62. Jeppesen TD, Madsen KL, Poulsen NS, Løkken N, Vissing J. Exercise testing, physical training and fatigue in patients with mitochondrial myopathy related to mtDNA mutations. J Clin Med 2021; 10(8):1796. DOI: https://doi.org/10.3390/jcm10081796

63. Taivassalo T, Gardner JL, Taylor RW, Schaefer AM, Newman J, Barron MJ, Haller RG, Turnbull DM. Endurance training and detraining in mitochondrial myopathies due to single large-scale mtDNA deletions. Brain 2006; 129(Pt 12):3391-3401. DOI: https://doi.org/10.1093/brain/awl282
64. Guo C, Sun L, Chen X, Zhang D. Oxidative stress, mitochondrial damage and neurodegenerative diseases. Neural Regen Res 2013; 8(21):2003-2014. DOI:

https://doi.org/10.3969/j.issn.1673-5374.2013.21.009

65. Kuszak AJ, Espey MG, Falk MJ, Holmbeck MA, Manfredi G, Shadel GS, Vernon HJ, Zolkipli-Cunningham Z. Nutritional interventions for mitochondrial OXPHOS deficiencies: Mechanisms and model systems. Annu Rev Pathol 2018; 13:163-191. DOI: https://doi.org/10.1146/annurev-pathol-020117-04364 4

66. Elbaky NAA, El-Orabi NF, Fadda LM, Abd-Elkader $\mathrm{OH}$, Ali HM. Role of N-Acetylcysteine and coenzyme Q10 in the amelioration of myocardial energy expenditure and oxidative stress, induced by carbon tetrachloride intoxication in rats. Dose Response 2018; 16(3):1559325818790158. DOI: https://doi.org/10.1177/1559325818790158

67. Kunze M, Berger J. The similarity between N-terminal targeting signals for protein import into different organelles and its evolutionary relevance. Front Physiol 2015; 6:259. DOI: https://doi.org/10.3389/fphys.2015.00259

68. Diodato D, Ghezzi D, Tiranti V. The mitochondrial aminoacyl tRNA synthetases: Genes and syndromes. Int J Cell Biol 2014; 2014:787956. DOI: https://doi.org/10.1155/2014/787956

69. Zhao L. Mitochondrial DNA degradation: A quality control measure for mitochondrial genome maintenance and stress response. Enzymes 2019; 45:311-341. DOI: https://doi.org/10.1016/bs.enz.2019.08.004

70. Moretton A, Morel F, Macao B, Lachaume P, Ishak L, Lefebvre M, Garreau-Balandier I, Vernet $P$, Falkenberg M, Farge G. Selective mitochondrial DNA degradation following double-strand breaks. PLoS One 2017; 12(4):e0176795. DOI: https://doi.org/10.1371/journal.pone.0176795

71. Zekonyte U, Bacman SR, Smith J, Shoop W, Pereira CV, Tomberlin G, Stewart J, Jantz D, Moraes CT. Mitochondrial targeted meganuclease as a platform to eliminate mutant mtDNA in vivo. Nat Commun 2021; 12(1):3210. DOI: https://doi.org/10.1038/s41467-021-23561-7 